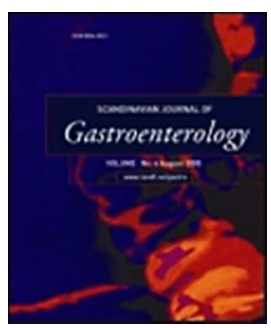

\title{
Patient radiation dose and fluoroscopy time during ERCP: a single-centre, retrospective study of influencing factors
}

\begin{tabular}{|r|l|}
\hline Journal: & Scandinavian Journal of Gastroenterology \\
\hline Manuscript ID & Draft \\
\hline Manuscript Type: & Original Article \\
\hline Date Submitted by the Author: & n/a \\
\hline Complete List of Authors: & $\begin{array}{l}\text { Saukko, Ekaterina; TYKS, The medical imaging centre of southwest Finland } \\
\text { Grönroos, Juha; TYKS, Division of Digestive Surgery and Urology } \\
\text { Salminen, Paulina; TYKS, Division of Digestive Surgery and Urology } \\
\text { Henner, Anja; Oulun Seudun Ammattikorkeakoulu, School of Health and } \\
\text { Social Care } \\
\text { Nieminen, Miika T.; Oulun yliopistollinen sairaala, Department of Diagnostic } \\
\text { Radiology }\end{array}$ \\
\hline Keyword: & ERCP \\
\hline &
\end{tabular}




\title{
Patient radiation dose and fluoroscopy time during ERCP: a single- centre, retrospective study of influencing factors
}

\author{
Ekaterina Saukko, MSc ${ }^{1}$, Juha M. Grönroos, MD, $\mathrm{PhD}^{2,3}$, Paulina \\ Salminen, $\mathrm{MD}, \mathrm{PhD}^{2,3}$, Anja Henner, $\mathrm{PhD}^{4}$, Miika T. Nieminen, $\mathrm{PhD}^{5,6,7}$ \\ ${ }^{1}$ The Medical Imaging Centre of Southwest Finland, Turku University Hospital, \\ Kiinamyllynkatu 4-8, PO Box 52, 20521 Turku, Finland \\ ${ }^{2}$ Division of Digestive Surgery and Urology, Turku University Hospital, \\ Kiinamyllynkatu 4-8, PO Box 52, 20521 Turku, Finland \\ ${ }^{3}$ Department of Surgery, University of Turku, Kiinamyllynkatu 10, 20520 Turku,
} Finland

${ }^{4}$ School of Health and Social Care, Oulu University of Applied Sciences, Kiviharjuntie 4, 90220 Oulu, Finland

${ }^{5}$ Research Unit of Medical Imaging, Physics and Technology, University of Oulu, PO Box 5000, 90014 Oulu, Finland
${ }^{6}$ Department of Diagnostic Radiology, Oulu University Hospital, PO Box 50, 90029 Oulu, Finland
${ }^{7}$ Medical Research Center Oulu, University of Oulu and Oulu University Hospital, PO Box 5000, 90014 Oulu, Finland

Correspondence: Ekaterina Saukko, The Medical Imaging Centre of Southwest Finland, Turku University Hospital, Kiinamyllynkatu 4-8, PO Box 52, 20521 Turku, Finland. Telephone: +35823130645. E-mail: ekaterina.saukko@tyks.fi

Telephone numbers and email addresses of other authors: Juha M. Grönroos, +35823131234 , juha.gronroos@tyks.fi; Paulina Salminen, +35823130542, paulina.salminen@.tyks.fi; Anja Henner, +358503670361, anja.henner@oamk.fi; Miika T. Nieminen, +35883152462, miika.nieminen@oulu.fi 
Ekaterina Saukko, RT, MSc, is a Research Coordinator at Turku University Hospital and PhD student at University of Oulu Graduate School, Finland. Her current research focuses on optimisation of radiation protection of the patients during ERCP. Juha Grönroos is Professor of Gastroenterological Surgery at University of Turku and Chief Surgeon at Division of Gastroenterological Surgery and Urology. His main research topics include mini-invasive surgery such as endoscopic pancreatobiliary surgery as well as infectious and inflammatory diseases such as acute appendicitis and acute pancreatitis. Paulina Salminen, MD, PhD, is a senior specialist in digestive surgery working at Turku University Hospital. Her main research topics are acute appendicitis and bariatric surgery. Anja Henner, $\mathrm{PhD}$, Principal lecturer is responsible for the R\&D in the Degree program of Radiography and Radiotherapy in Oulu University of Applied Sciences (OUAS) since year 1998. Her research and development interests are in radiation protection and digital imaging including quality assurance. Miika T. Nieminen, PhD, is Professor of Medical Physics at University of Oulu and Chief Physicist at Oulu University Hospital, Finland. His research interests include development of MRI and x-ray based imaging methods for tissue characterisation, and radiation protection. He is Fellow of International Society for Magnetic Resonance in Medicine.

A word count of manuscript: abstract 249 words, main text 3750 words 


\title{
Patient radiation dose and fluoroscopy time during ERCP: a single- centre, retrospective study of influencing factors
}

\author{
Objectives Recently, both the number and the complexity with associated \\ increased technical difficulty of therapeutic ERCP procedures have significantly \\ increased resulting in longer procedural and fluoroscopy times. During ERCP, \\ the patient is exposed to ionizing radiation and the consequent radiation dose \\ depends on multiple factors. The aim of this study was to identify factors \\ affecting fluoroscopy time and radiation dose in patients undergoing ERCP.
} Materials and methods Data related to patient demographics, procedural characteristics and radiation exposure in ERCP procedures $(n=638)$ performed between August 2013 and August 2015 was retrospectively reviewed and analysed. Statistically significant factors identified by univariate analyses were included in multivariate analysis with fluoroscopy time (FT) and dose area product (DAP) as dependent variables. Effective dose (ED) was estimated from DAP measurements using conversion coefficient. Results The factors independently associated with increased DAP during ERCP were age, gender, radiographer, complexity level of ERCP, cannulation difficulty grade, bile duct injury and biliary stent placement. In multivariate analysis the endoscopist, the complexity level of ERCP, cannulation difficulty grade, pancreatic duct leakage, bile duct dilatation and brushing were identified as predictors for a longer FT. The mean DAP, FT, number of acquired images and ED for all ERCP procedures were $2.33 \mathrm{~Gy} \cdot \mathrm{cm} 2,1.84 \mathrm{~min}, 3$ and $0.61 \mathrm{mSv}$, respectively. Conclusions Multiple factors had an effect on DAP and FT in ERCP. The awareness of these factors may help to predict possible prolonged procedures causing a higher radiation dose to the patient and thus facilitate the use of appropriate precautions.

Keywords: cholangiopancreatography, endoscopic retrograde; radiation exposure; radiation protection; fluoroscopy; multivariate analysis

\section{Introduction}

Endoscopic retrograde cholangiopancreatography (ERCP), used as a gold standard in the endoscopic treatment of pancreatobiliary disorders, continues to be one of the most complex and technically demanding gastrointestinal procedures [1-3]. This invasive 
procedure requires the use of fluoroscopy and therefore places both the patient and the endoscopy staff at risk of radiation-induced injury [4]. Risks associated with ionizing radiation include cataract, infertility, skin injury, hair loss, malignancy, and genetic effects [5].

During ERCP, the patient is exposed to the primary beam and consequently receives a higher radiation dose compared to endoscopy staff, whose major source of radiation exposure is caused by scattered radiation from the patient [6]. Over the years, both the number and the complexity with associated increased technical difficulty of therapeutic ERCP procedures have significantly increased resulting in longer procedural [7] and fluoroscopy times $[8,9]$. Prolonged fluoroscopy time to the same skin area, irradiation through thick body masses as well as an extensive use of high-dose rate modes may produce a high radiation dose to the patient's skin and increase the risk of radiation-induced skin injury $[10,11]$. Skin injury may occur if the skin dose exceeds a threshold dose of 2 Grey (Gy) for transient erythema [12]. Grey (Gy) is a unit of absorbed radiation dose, defined as 1 joule of energy deposited in 1 kilogram of mass (1 $\mathrm{J} / \mathrm{kg}$ ). According to International Commission on Radiological Protection (ICRP), ERCP procedure has the potential to impart skin doses exceeding 1 Gy [13].

In order to understand both the optimization of the radiation exposure in fluoroscopy procedures and minimizing the risk of radiation-induced injury, it is essential to be familiar with the factors influencing patient radiation dose $[1,6,11]$. Previously, it has been found that the type of x-ray unit, anatomical location of pathology, difficult cannulation, annual volume and experience of endoscopist, trainee involvement, complexity of procedure, sphincterotomy, stent insertion, balloon dilatation, stone extraction, and other interventions influenced on the exposure levels in ERCP [8, 9, 14-22]. A randomized trial by Uradomo et al. [22] showed that a 
behavioural intervention (time limiting the fluoroscopy to 3 seconds each time the footoperated switch is depressed) was associated with a $16 \%$ lower fluoroscopy time. Decreasing the distance between the endoscopy and fluoroscopy screens in the ERCP was also found to reduce a fluoroscopy time by 1.4 minutes [23].

Although several studies have been performed to identify factors associated with prolonged fluoroscopy time and increased radiation exposure in ERCP, these have not been completely clarified [19] and the impact of difficulty degree of ERCP procedure on patient radiation dose remains unclear. The aim of the present study was to determine factors affecting fluoroscopy time and radiation dose in patients undergoing ERCP in a single tertiary care hospital performing some 450-500 ERCPs annually.

\section{Materials and methods}

This study is a retrospective data review covering prospective data collection in an already running database, previously initiated for quality control and for scientific purposes in the endoscopy unit at Turku University Hospital, Finland. The database comprises data from ERCP including patients' demographics, indications for ERCP, cannulation time and cannulation methods, performed interventions and used techniques, post-ERCP diagnosis, total procedural time and the endoscopist. Similarly, the specific reason for possible unsuccessful procedure was registered. All consecutive patients undergoing ERCP between August 2013 and August 2015 were enrolled in this study.

The data of included consecutive ERCP patients $(\mathrm{n}=756)$ was complemented by radiation quantities, such as dose area product (DAP, $\left.\mathrm{Gy} \cdot \mathrm{cm}^{2}\right)$, fluoroscopy time $(\mathrm{FT}$, $\min$ ) and the number of radiographic images that were retrieved directly from Radiology Information System (RIS) and Picture Archiving and Communication System (PACS). DAP is a product of the air kerma (Gy) and exposed area of the skin 
$\left(\mathrm{m}^{2}\right)$ providing a good estimation of the total radiation energy delivered to the patient during a procedure $[15,24]$. Effective dose (ED) is an indicator of the risk for stochastic effects (cancer, genetic effects) [25] and ED (measured in Sieverts, Sv) was estimated from DAP measurements by a conversion coefficient of $0.26 \mathrm{mSv} /\left(\mathrm{Gy} \cdot \mathrm{cm}^{2}\right)$ [26]. ED allows a comparison across different radiological procedures and various hospitals [25].

Based on clinical guideline from European Society of Gastrointestinal Endoscopy (ESGE), the cannulation in ERCP was considered being difficult if more than 5 minutes was spent attempting to cannulate following visualization of the papilla [27]. The cannulation difficulty was graded according to the time needed to achieve a successful selective deep cannulation as follows: $<1 \min (1=$ easy), 1-5 min ( $2=$ intermediate),$>5 \mathrm{~min}(3=$ difficult $)$. The cannulation time was measured by an assisting radiographer and counted from the first touch to papilla to a successful cannulation of the desired duct. Procedural complexity of ERCP was determined using the grading system proposed by the working group of the American Society for Gastrointestinal Endoscopy (ASGE) Quality Committee with scores ranging from 1 (simple ERCP) to 4 (the most complex ERCPs) based on clinical context and performed interventions [28]. The grades are defined as follows: grade 1 (biliary stent removal or exchange, brushing), grade 2 (biliary stone extraction $<10 \mathrm{~mm}$, treating biliary leaks, treating extrahepatic benign and malignant strictures), grade 3 (biliary stone extraction $>10 \mathrm{~mm}$, minor papilla cannulation, removing of internally migrated biliary stents, management of acute or recurrent pancreatitis, treating pancreatic strictures, removing mobile pancreatic stones and stones $<5 \mathrm{~mm}$, treating benign strictures in hilum and above) and grade 4 (removing internally migrated pancreatic stents, removing impacted pancreatic stones and stones $>5 \mathrm{~mm}$, intrahepatic stones, pseudocyst drainage, ampullectomy). Because of the small number of ERCP procedures of 4 th degree 
appears in this data $(n=5)$, the complexity grades 3 and 4 were combined into one group.

All ERCP procedures were performed for clinical symptoms or for pathologic findings detected in other examinations. Five experienced endoscopists performed the procedures and those performed by a trainee were excluded from the study. Patients were positioned on the left side for the ERCP and procedures were completed under conscious sedation with midatzolam and fentanyl administered by a nurse according to the instructions of the endoscopist. During ERCP, the fluoroscopy was operated by the endoscopist while fluoroscopy system was controlled by a radiographer. The same fluoroscopic system (MultiDiagnost Eleva, Philips Medical Systems, Best, The Netherlands) was used in ERCP throughout the study period, and it was equipped with a multipurpose $\mathrm{C}$-arm and with an image intensifier. The dose measuring device was integrated into the equipment. During ERCP pulsed fluoroscopy with lowest possible pulse rate of $1.5 \mathrm{fps}$ was used and the $\mathrm{x}$-ray beam was modified by collimating the field size to the region of interest.

Statistical analysis was performed using the IBM SPSS Statistics for Windows, Version 22 (IBM Corp. 2013 Armonk, NY). Failed ERCP procedures and those with missing radiation exposure data were excluded from the final analysis. Categorical data were presented as frequency and percentage. Continuous data were expressed as mean \pm standard deviation (SD), range, standard error (SE) or median with interquartile range (IQR) as indicated. Differences in continuous variables were tested using MannWhitney U-test or Kruskal-Wallis test for nonparametric data. Factors associated with increased FT and DAP in ERCP were evaluated by univariate analysis performed with a logarithmic transformation of the DAP and FT due to asymmetric distributions. Statistically significant variables were included in the multivariate analysis. Bonferroni 
adjustments were applied for all post-hoc tests to adjust p-values for multiple comparisons. A p value less than 0.05 was considered statistically significant.

Institutional review board approval was obtained at the Turku University Hospital. According to Finnish Medical Research Act [29], the retrospective nature of this study does not require the approval from local ethics committee. Data was anonymized before statistical analysis prohibiting subsequent patient identification.

\section{Results}

Altogether 638 out of 756 ERCP procedures were analysed in this study to determine factors affecting fluoroscopy time and radiation dose to patient, as the failed procedures $(n=86)$ and those performed by a trainee $(n=27)$ or with missing radiation exposure data $(n=5)$ were excluded from the study. Common reasons for failed ERCP were unsuccessful cannulation $(n=37,43 \%)$ and gastroduodenal obstruction $(n=26,30 \%)$. $48 \%$ of the patients were male and the mean age for all patients was 66.0 years (Table 1). The main indication for ERCP was bile duct stone removal $(n=261,41 \%)$ followed by malignant strictures $(n=100,16 \%)$ and jaundice of unknown etiology $(n=80,13 \%)$. Most of the ERCP procedures $(n=463,73 \%)$ were carried out in patients with native papilla. The time needed to achieve a successful selective deep cannulation of the desired duct was $<1 \mathrm{~min}$ in $40 \%, 1-5 \mathrm{~min}$ in $34 \%$ and $>5 \mathrm{~min}$ in $26 \%$ of those ERCP cases where the time was recorded $(\mathrm{n}=537)$. The cannulation success rate was $95 \%$ in patients with free access to papilla. Typical findings in ERCP were bile duct stones $(n=208,33 \%)$, benign and malignant bile duct strictures $(n=174,27 \%)$ and normal anatomy $(\mathrm{n}=65,10 \%)$. [Table 1 near here]

The results showed a large variation in radiation quantities (Table 2). The mean DAP, FT and number of radiographic images for all ERCP procedures were $2.33 \pm 1.79$ (range 0.09-14.19) Gy·cm2, 1.84 \pm 1.56 (range 0.11-9.57) min and 3.02 \pm 1.83 (range 0- 
11), respectively. A positive linear correlation was observed between DAP and FT ( $r s=0.73, p<0.01)$, as well as between DAP and the number of radiographic images $(\mathrm{rs}=0.52, \mathrm{p}<0.01)$. The average ED of the ERCP patient was $0.61 \pm 0.47$ (range 0.023.69) $\mathrm{mSv}$. Male gender was associated with a greater radiation exposure $(2.55 \pm 1.92$ Gy $\cdot \mathrm{cm} 2)$ compared to females $(2.11 \pm 1.65 \mathrm{~Gy} \cdot \mathrm{cm} 2)$ and the difference was statistically significant $(\mathrm{p}=0.001)$. Patients who underwent ERCP for the first time received a lower radiation dose $(2.21 \pm 1.67 \mathrm{~Gy} \cdot \mathrm{cm} 2)$ than those who had repeat ERCP $(2.63 \pm 2.06$ Gy $\cdot \mathrm{cm} 2)$ procedure $(p=0.036)$. FT was also significantly longer in the repeat ERCP than in the primary one $(\mathrm{p}=0.024)$. Moreover, patients with suspected $(\mathrm{p}<0.001)$ or diagnosed $(\mathrm{p}=0.01)$ bile duct injury had a higher radiation dose than those with bile duct stones. Similarly, post-ERCP diagnosis of pancreatic duct leakage was associated with a higher DAP $(\mathrm{p}<0.001)$ and longer FT $(\mathrm{p}=0.03)$. Increased image acquisition during ERCP was noted in patients with bile duct stricture $(\mathrm{p}<0.001)$ and bile duct injury $(p<0.001)$. The mean of acquired images was also high in patients with pancreatic duct leakage $(\mathrm{n}=12)$, but statistical significance was not reached. [Table 2 near here]

The difficult cannulation with cannulation time exceeding 5 min was related to increased DAP and prolonged FT compared to those ERCP procedures with cannulation lasting between 1 and $5 \min (\mathrm{DAP} p=0.012$; FT $\mathrm{p}<0.001$ ) or being under $1 \min$ (DAP $\mathrm{p}=0.004 ;$ FT $\mathrm{p}<0.001)$. Based on ERCP complexity grading system, the majority $(60 \%)$ of performed ERCP procedures in this study were of complexity grade 2 (Table 2). The grade 1 procedures constituted $20 \%$ and grade 3 and 4 combined were $21 \%$. There was a significant difference in DAP between the ERCP complexity grades 1 and $3(p=0.004)$ as well as between grades 2 and $3(p<0.001)$. The same statistical difference was noted in FT for complexity grade 1 versus grade $3(\mathrm{p}<0.001)$ and complexity grade 2 versus 3 $(\mathrm{p}<0.001)$. The mean DAP $(2.84 \pm 1.85 \mathrm{~Gy} \cdot \mathrm{cm} 2)$ and FT $(2.45 \pm 1.71 \mathrm{~min})$ were highest 
in procedures of $3^{\text {rd }}$ grade (Table 2). However, the mean DAP and FT did not increase in concert with the increase in complexity scale.

Three out of five endoscopists performed higher number of ERCP procedures of $3^{\text {rd }}$ grade complexity and difference in relative proportion of difficult procedures was also observed between the endoscopists (Table 3). The mean FT was substantially longer in ERCP procedures performed by endoscopist $1(2.11 \pm 1.87 \mathrm{~min}, \mathrm{p}<0.001), 3$ $(1.81 \pm 1.40 \mathrm{~min}, \mathrm{p}<0.001), 4(1.79 \pm 1.58 \mathrm{~min}, \mathrm{p}<0.001)$ and $5(2.25 \pm 1.27 \mathrm{~min}, \mathrm{p}<0.001)$ compared with endoscopist $2(0.92 \pm 0.91 \mathrm{~min})$. Regarding DAP, the differences between endoscopists did not reach the statistical significance. There were no significant differences in image acquisition between endoscopists either. In addition, it was found that DAP varied in ERCP depending on who of the ten radiographers was controlling the fluoroscopy system $(\mathrm{p}<0.001)$. The highest mean DAP was $4.06 \pm 2.31 \mathrm{~Gy} \cdot \mathrm{cm} 2$ in procedures with involvement of radiographer 6 . Nevertheless, there were no significant differences among radiographers in FT or procedural complexity of performed ERCP procedures (Fig. 1). [Table 3 near here] [Figure 1 near here]

The univariate and multivariate analysis with log-transformed data identified several factors as predictors for higher DAP (Table 4) and prolonged FT (Table 5) in ERCP. In univariate analysis, the variables that were found to be significantly associated with both radiation quantities were complexity level of ERCP, cannulation difficulty grade, bile duct stricture, bile duct injury and pancreatic duct leakage. Age, gender, radiographer involved in ERCP, jaundice and suspicion of bile duct injury were associated statistically only with DAP, whereas endoscopist performing ERCP was related only to FT. Multivariate modelling performed with DAP as dependent variable showed that clinical indication and post-ERCP-diagnosis were highly correlated, if included in the same model. Based on this, the indication was excluded from the final 
analysis. In addition, the types of interventions performed during ERCP were included directly in multivariate analysis. To assess the independent effect of certain variables on DAP and FT, a total of 3 models were selected in multivariate analysis for both dependent variables.

Multivariate analysis showed that gender (female vs male), age ( $<35$ vs $36-65$ years), radiographer ( 1 vs 2, 4, 5, 6, 9, 10), complexity level of ERCP (grade 2 vs 3 ) and cannulation difficulty grade (in all comparisons) were independently associated with increased DAP in all selected models (Table 4). Post-ERCP diagnoses such as bile duct stricture $(p<0.001)$, cholangitis $(p=0.01)$, bile duct injury $(p<0.001)$ and other $(p=0.03)$ were found to be associated with a higher DAP in the multivariate model 1, but when interventions were included in the model (model 2$)$, only bile duct injury $(p<0.001)$ remained significant. The biliary stent placement was the only intervention performed during ERCP that independently predicted a higher DAP.

Similarly, factors independently related to prolong FT (Table 5) in all selected models of multivariate analysis were endoscopist (in all comparisons), complexity level of ERCP (grade 2 vs 3 ) and cannulation difficulty grade (in all comparisons). PostERCP diagnoses such as bile duct stricture $(\mathrm{p}=0.03)$, cholangitis $(\mathrm{p}=0.04)$, bile duct injury $(p<0.001)$ and pancreatic duct leakage $(p=0.02)$ were associated with longer FT in multivariate model (model 1), but when interventions were included in the model (model 2$)$, only pancreatic duct leakage $(\mathrm{p}=0.03)$ remained significant. Interventions like bile duct dilatation and brushing were identified by multivariate analysis as predictors for longer FT. Furthermore, the multivariate analysis revealed that biliary stent placement was also associated with longer FT, when the diagnosis was removed from the model (model 3). [Table 4 near here] [Table 5 near here] 


\section{Discussion}

In recent years, there has been a growing interest generated by research in the field of radiation exposure of both the patient and medical staff during ERCP procedures, as it has been recognized that ERCP requires the same level of radiation protection practice as all other interventional radiological procedures [1, 3, 4, 6, 8, 9, 14-23, 30-37]. This study was performed to identify factors associated with FT and radiation dose measured by DAP in patients undergoing ERCP in a single tertiary care hospital. The factors independently associated with increased DAP during ERCP were gender, age, radiographer, complexity level of ERCP, cannulation difficulty grade, bile duct injury and biliary stent placement. Endoscopist, complexity level of ERCP, cannulation difficulty grade, pancreatic duct leakage, bile duct dilatation and brushing were identified by multivariate analysis as predictors for longer FT. The mean DAP, FT, number of acquired images and ED for all ERCP procedures were $2.33 \mathrm{~Gy} \cdot \mathrm{cm} 2,1.84$ min, 3 and $0.61 \mathrm{mSv}$, respectively. Assuming a linear response at low doses, the combined detriment from stochastic effects has remained unchanged at around 5\% per Sievert [25] and it follows that the lifetime cancer risk from ERCP is approximately $0.003 \%$.

Previous studies investigating factors related to increased radiation exposure in patients during ERCP have been focused mainly on FT [8, 17, 19-21, 23, 37], only some studies have included DAP in the analysis $[9,15,18,38]$. There is a good correlation between FT and DAP in ERCP according to the literature [30, 32, 34-36, 38], however in some studies a correlation was not found [4, 39]. FT is one of the features that determine radiation exposure, but as a surrogate measure, FT is not sufficient in monitoring patient radiation doses since it has several limitations [34, 40, 41]. For instance, some factors affecting DAP are not included in FT, such as patient 
size and position, imaging geometry, settings of the fluoroscopy equipment, collimation, magnification, angulation, acquisition images and filtration [20, 33, 34, 42]. The results of the present study also revealed that variables associated with increased DAP and prolonged FT in ERCP were partly different.

Male gender was associated with a higher DAP, likely attributable to the larger size of male patients. Larger patient size requires a higher radiation dose to obtain adequate image quality than the normal-sized patient [43]. Unfortunately, body weights of the patients were not registered at the time when original data was collected, as this information could have been provided an additional benefit for this study. Younger patients, i.e. under 35 years, received a lower radiation dose than the patients between 36 and 65 years, probably owing to simpler ERCP procedures performed in that age group and for better dose optimisation practice. In a previous study by RodríguezPerálvarez et al. [38] an independent association was observed between younger patients and a higher DAP in ERCP, however, the authors did not identify any logical explanation for it. It is essential to pay a special attention to the radiation protection of young patient, but as life expectancy increases, highlighting the benefits of radiation protection in the elderly is also important [44].

The observed significant differences in FT between endoscopists were likely related to procedural complexity in ERCP, as endoscopists who performed more ERCPs with a greater procedural complexity had a longer FT on average. There seemed to be differences in DAP among endoscopists as well, but they did not reach the statistical significance in this study. Differences in training, experience and individual practice patterns of endoscopists could also explain these variations in FT and DAP [37]. Previous studies have demonstrated that ERCP volume of endoscopist fewer than 200 procedures in the preceding year has been associated with a longer FT [20] and 
increased DAP [15]. In addition, an involvement of a trainee in ERCP procedures has been noticed to associate with increase in FT [16, 17, 20, 21]. The differences in DAP among radiographers are likely the result of different collimation practices during ERCP, since significant differences in FT or procedural complexity of performed procedures were not found. This association has not been reported previously. Even though a fluoroscopy system includes multiple settings that can be adjusted during ERCP, radiographers at our institution typically modify only the collimation.

Collimation of the irradiated surface area to the region of interest is important, because it reduces the radiation exposure of the patient and improves image quality by limiting the amount of scattered radiation to the detector [45].

Bile duct injury was found to have a significant impact on DAP, which probably is related to increase in use of image acquisition during ERCP as high image quality is needed to visualize fine details and subtle contrast differences in the anatomy of interest. FT was also longer for patients with bile duct injury, likely due to additional interventions performed during ERCP, such as sphincterotomy and stent placement. This difference reached the statistical significance in univariate analysis and in one of the multivariate models. The same effect on DAP and FT was observed with diagnosis of pancreatic duct leakage, though association with FT was stronger. Multivariate analysis revealed that interventions such as bile duct dilatation and brushing predicted a longer FT in ERCP. Biliary stent placement was significantly related to higher DAP and an association between biliary stent placement and FT was also found in one of the multivariate models. All these significant variables have already been reported previously $[8,17-19,21,23,37,46]$ and without a doubt these interventions require fluoroscopy to confirm proper placement of instruments and to assist in the endoscopic therapy. The use of balloon catheter as a dilatator is often followed by cholangiogram, 
consequently requiring longer FT. One possible reason for the stronger association of the biliary stent placement with the DAP instead of FT is that the outcome of stent insertion is usually documented at our hospital by image acquisition.

Difficult and complex procedures typically take more time, require prolonged fluoroscopy time and therefore associate with a higher radiation dose [47]. Complexity level of ERCP and cannulation difficulty grade were both independently associated with a higher DAP and longer FT in present study. It seems that cannulation difficulty is a better predictor of the increase in DAP and FT than the grading system of ERCP complexity. Performed interventions during ERCP were somewhat associated with the complexity level of ERCP, since significant differences in DAP and FT were observed only between the complexity grades 2 and 3 (multivariate models 2 and 3). ASGE [28] complexity grading system was originally developed for a method of evaluating outcomes/adverse events based on the degree of procedural difficulty. In addition, this grading system does not take into consideration the number of interventions performed or the number of instruments used during ERCP as these both has been found to be significant and have an effect on FT [37]. Recently, a new "HOUSE" -grading scale for ERCP complexity was developed by Olsson et al. [48], which classified procedures into three classes in line with the modern endoscopic treatment procedures in ERCP.

In conclusion, multiple factors were found to affect DAP and FT in ERCP. The awareness of these factors may help to predict possible prolonged procedures causing a higher radiation dose to the patient and thus facilitate the use of appropriate precautions. This is particularly important in the complex cases, as difficult papillary cannulation and complexity level of ERCP were both independently associated with a higher DAP and longer FT. Minimizing patient radiation dose in ERCP remains an essential goal in the optimisation process and the endoscopist has the most significant role in the amount 
of fluoroscopy time used during ERCP. Optimization of patient exposure will consequently improve the radiation protection of the staff involved in ERCP procedures. A good radiation protection practice can be achieved through continuing education and training of medical staff as well as by ensuring quality of fluoroscopy equipment.

Disclosure of interest Paulina Salminen has received lecture fees from Merck and Lilly. The remaining authors declare that they have no conflicts of interest.

\section{References}

1. Kachaamy TA, Faigel DO. Improving ERCP quality and decreasing risk to patients and providers. Expert Rev Gastroenterol Hepatol. 2013;7:531-540.

2. Grönroos JM. Clinical success of ERCP procedures in nonagenarian patients with bile duct stones. Minim Invasive Ther Allied Technol. 2011;20:146-149.

3. Boix J, Lorenzo-Zúniga V. Radiation dose to patients during endoscopic retrograde cholangiopancreatography. World J Gastrointest Endosc. 2011;3:140-144.

4. Tsapaki V, Paraskeva KD, Mathou N, et al. Patient and endoscopist radiation doses during ERCP procedures. Radiat Prot Dosim. 2011;147:111-113.

5. United Nations Scientific Committee on the Effects of Atomic Radiation. Sources, Effects and Risks of Ionizing Radiation. UNSCEAR 2012 Report. Report to the General Assembly with Scientific Annexes. United Nations publication sales E.16.IX.1. NY: United Nations; 2015.

6. Amis ES Jr. Risk of radiation exposure in the endoscopy suite: principles, cautions, and risks to patient and endoscopy staff. Tech Gastrointest Endosc. 2007;9:213217.

7. Mehta PP, Sanaka MR, Parsi MA, et al. Association of procedure length on outcomes and adverse events of endoscopic retrograde cholangiopancreatography. Gastroenterol Rep (Oxf). 2014;2:140-144. 
8. Alkhatib AA, Abdel Jalil AA, Faigel DO, et al. Anatomical location of pathology is predictive of prolonged fluoroscopy time during ERCP: a multicenter American study. Dig Dis Sci. 2015;60:1787-1792.

9. Churrango G, Deutsch JK, Dinneen HS, et al. Minimizing radiation exposure during ERCP by avoiding live or continuous fluoroscopy. J Clin Gastroenterol. 2015;49:e96-100.

10. Wagner LK. Radiation injury is a potentially serious complication to fluoroscopically-guided complex interventions. Biomed Imaging Interv J. 2007;3:e22.

11. Killewich LA, Falls G, Mastracci TM, et al. Factors affecting radiation injury. J Vasc Surg. 2011;53:9S-14S.

12. Balter S, Hopewell JW, Miller DL, et al. Fluoroscopically guided interventional procedures: a review of radiation effects on patients' skin and hair. Radiology. 2010;254:326-341.

13. International Commission on Radiological Protection. Radiological protection in fluoroscopically guided procedures outside the imaging department. ICRP Publication 117. Ann ICRP. 2010;40:1-102.

14. Tsapaki V, Paraskeva KD, Tsalafoutas IA, et al. The impact of x-ray unit type used for endoscopic retrograde cholangiopancreatography procedures on patient doses. Radiat Prot Dosimetry. 2016;171:503-508.

15. Liao C, Thosani N, Kothari S, et al. Radiation exposure to patients during ERCP is significantly higher with low-volume endoscopists. Gastrointest Endosc. 2015;81:391-398.

16. Oztas E, Parlak E, Kucukay F, et al. The impact of endoscopic retrograde cholangiopancreatography education on radiation exposure to experienced endoscopist: 'trainee effect'. Dig Dis Sci. 2012;57:1134-1143.

17. Kim E, McLoughlin M, Lam EC, et al. Prospective analysis of fluoroscopy duration during ERCP: critical determinants. Gastrointest Endosc. 2010;72:50-57.

18. Lorenzo-Zúñiga V, Alvarez MA, Moreno de Vega V, et al. Predictive factors of radiation dose in ERCP: a prospective study in 2 tertiary centers. Surg Laparosc Endosc Percutan Tech. 2013;23:266-270.

19. Katsinelos P, Gatopoulou A, Gkagkalis $\mathrm{S}$, et al. A prospective analysis of factors influencing fluoroscopy time during therapeutic ERCP. Ann Gastroenterol. $2012 ; 25: 338-344$. 
20. Jorgensen JE, Rubenstein JH, Goodsitt MM, et al. Radiation doses to ERCP patients are significantly lower with experienced endoscopists. Gastrointest Endosc. 2010;72:58-65.

21. Romagnuolo J, Cotton PB. Recording ERCP fluoroscopy metrics using a multinational quality network: establishing benchmarks and examining timerelated improvements. Am J Gastroenterol. 2013;108:1224-1230.

22. Uradomo LT, Goldberg EM, Darwin PE. Time-limited fluoroscopy to reduce radiation exposure during ERCP: a prospective randomized trial. Gastrointest Endosc. 2007;66:84-89.

23. Jowhari F, Hopman WM, Hookey L. A simple ergonomic measure reduces fluoroscopy time during ERCP: A multivariate analysis. Endosc Int Open. 2017;5:E172-E178.

24. International Commission on Radiation Units and Measurements. Patient dosimetry for $\mathrm{x}$ rays used in medical imaging. Report 74. J ICRU. 2005;5: 1-113.

25. International Commission on Radiological Protection. The 2007 recommendations of the International Commission on Radiological Protection. ICRP publication 103. Ann ICRP. 2007;37: 1-332.

26. National Council on Radiation Protection and Measurements. Ionizing radiation exposure of the population of the United States. NCRP Report 160. Bethesda, MD; 2009.

27. Testoni PA, Mariani A, Aabakken L, et al. Papillary cannulation and sphincterotomy techniques at ERCP: European Society of Gastrointestinal Endoscopy (ESGE) Clinical Guideline. Endoscopy. 2016;48:657-683.

28. Cotton PB, Eisen G, Romagnuolo J, et al. Grading the complexity of endoscopic procedures: results of an ASGE working party. Gastrointest Endosc. 2011;73:868-874.

29. Laki lääketieteellisestä tutkimuksesta 488/1999 [Medical Research Act No. 488/1999]. 1999 Nov 1 [cited 2017 Oct 20]. Available from: https://www.finlex.fi/fi/laki/ajantasa/1999/19990488. Finnish.

30. Seo D, Kim KH, Kim JS, et al. Evaluation of radiation doses in patient and medical staff during endoscopic retrograde cholangiopancreatography procedures. Radiat Prot Dosimetry. 2016;168:516-522. 
31. Sulieman A, Elzaki M, Alkhorayef M, et al. Assessment of patient dose and radiogenic risks during endoscopic retrograde cholangiopancreatography. Appl Radiat Isot. 2016;117:65-69.

32. Hadjiconstanti AC, Messaris GA, Thomopoulos KC, et al. Patient dose during therapeutic endoscopic retrograde cholangiopancreatography procedure. Radiat Prot Dosimetry. 2017; 173:380-382.

33. Tsapaki V, Paraskeva DK, Giannakopoulos A, et al. Patient and Staff Radiation Exposure during Endoscopic Retrograde Cholangio-Pancreatography: Eight Years of Dose Monitoring. OMICS J Radiol. 2017;6:253.

34. Kachaamy T, Harrison E, Pannala R, et al. Measures of patient radiation exposure during endoscopic retrograde cholangiography: Beyond fluoroscopy time. World J Gastroenterol. 2015;21:1900-1906.

35. Saukko E, Henner A, Ahonen SM. Radiation exposure to patients during endoscopic retrograde cholangiopancreatography: A multicentre study in Finland. Radiography. 2015;21:131-135.

36. Saukko E, Henner A, Nieminen MT, et al. The establishment of local diagnostic reference levels in endoscopic retrograde cholangiopancreatography: a practical tool for the optimization and quality assurance management. Radiat Prot Dosimetry. 2017;173:338-344.

37. Kim E, McLoughlin M, Lam EC, et al. Retrospective analysis of radiation exposure during endoscopic retrograde cholagiopancreatography: critical determinants. Can J Gastroenterol. 2011;25:555-559.

38. Rodríguez-Perálvarez ML, Miñano-Herrrero JA, Hervás-Molina AJ, et al. Radio induced cancer risk during ERCP. Is it a real clinical problem? Rev Esp Enferm Dig. 2011;103:191-195.

39. Brambilla M, Marano G, Dominietto M, et al. Patient radiation doses and references levels in interventional radiology. Radiol Med. 2004;107:408-418.

40. Skripochnik E, Loh SA. Fluoroscopy time is not accurate as a surrogate for radiation exposure. Vascular. 2017;25:466-471.

41. Ghelani SJ, Glatz AC, David S, et al. Radiation dose benchmarks during cardiac catheterization for congenital heart disease in the United States. JACC Cardiovasc Interv. 2014;7:1060-1069. 
42. Dumonceau JM, Garcia-Fernandez FJ, Verdun FR, et al. Radiation protection in digestive endoscopy: European Society of Digestive Endoscopy (ESGE) guideline. Endoscopy. 2012;44:408-421.

43. Yanch JC, Behrman RH, Hendricks MJ, et al. Increased radiation dose to overweight and obese patients from radiographic examinations. Radiology. 2009;252:128-139.

44. Hernández L, Terradas M, Camps J, et al. Aging and radiation: bad companions. Aging Cell. 2015;14:153-161.

45. Walters TE, Kistler PM, Morton JB, et al. Impact of collimation on radiation exposure during interventional electrophysiology. Europace. 2012;14:16701673.

46. Kruit AS, Vleggaar FP, van Erpecum KJ, et al. No reduction of radiation dose following the introduction of dose-area product measurement in endoscopic retrograde cholangiopancreatography. Eur J Gastroenterol Hepatol. 2015;27:1454-1458.

47. World Gastroenterology Organisation. Radiation protection in the endoscopy suite. Minimizing radiation exposure for patients and staff in endoscopy: a joint ASGE/IAEA/WGO guideline. 2009 [cited 2017 Oct 20]. Available from: http://www.worldgastroenterology.org/guidelines/global-guidelines/radiationprotection-in-the-endoscopy-suite/radiation-protection-in-the-endoscopy-suiteenglish

48. Olsson G, Arnelo U, Swahn F, et al. The H.O.U.S.E. classification: a novel endoscopic retrograde cholangiopancreatography (ERCP) complexity grading scale. BMC Gastroenterol. 2017;17:38. 
Table 1 Patient demographics and procedural characteristics of 638 ERCP procedures

\begin{tabular}{|c|c|}
\hline Variables & Total \\
\hline \multicolumn{2}{|l|}{ Gender $[\mathrm{n}(\%)]$} \\
\hline Female & $330(51.7)$ \\
\hline Male & $308(48.3)$ \\
\hline Age $(y)[$ mean $\pm \mathrm{SD}]$ & $66.0 \pm 16.7$ \\
\hline \multicolumn{2}{|l|}{ Indication $[\mathrm{n}(\%)]$} \\
\hline Bile duct stones & $261(40.9)$ \\
\hline Malignant strictures & $100(15.7)$ \\
\hline Jaundice & $80(12.5)$ \\
\hline Cholangitis & $61(9.6)$ \\
\hline Chronic pancreatitis & $28(4.4)$ \\
\hline Suspicion of bile duct injury & $22(3.4)$ \\
\hline Pseudocyst & $8(1.3)$ \\
\hline Stent removal or exchange & $36(5.6)$ \\
\hline Other & $42(6.6)$ \\
\hline \multicolumn{2}{|l|}{ Type of ERCP [n (\%)] } \\
\hline Primary ERCP & $463(72.6)$ \\
\hline Repeat ERCP & $175(27.4)$ \\
\hline Total cannulation time ( $\min , n=537)$ [median (IQR)] & $1.67(0.49-5.2)$ \\
\hline \multicolumn{2}{|l|}{ Post-ERCP diagnosis [n (\%)] } \\
\hline Normal anatomy & $65(10.2)$ \\
\hline Bile duct stricture & $174(27.3)$ \\
\hline Bile duct stones & $208(32.6)$ \\
\hline Cholangitis & $48(7.5)$ \\
\hline Chronic pancreatitis & $26(4.1)$ \\
\hline
\end{tabular}


Pseudocyst

Bile duct dilatation

Bile duct injury

Stent problems

Pancreatic duct leakage

Other

Types of interventions $(\mathrm{n}=1229)$ [n (\%)]

Sphincterotomy

Biliary stone extraction

Bile duct dilatation

Biliary stent placement

Biliary stent removal

Pancreatic sphincterotomy

Pancreatic stone extraction

Pancreatic duct dilatation

Pancreatic stent placement

Pancreatic stent removal

Brushing

Other

Total procedural time ( $\min , n=542)$ [median (IQR)]
$6(0.9)$

$20(3.1)$

$22(3.4)$

$16(2.5)$

$12(1.9)$

$41(6.4)$

$366(29.8)$

$314(25.5)$

$135(11.0)$

$222(18.1)$

$70(5.7)$

$21(1.7)$

$3(0.2)$

$9(0.7)$

$22(1.8)$

$11(0.9)$

$34(2.8)$

$22(1.8)$

$17.0(12.0-25.0)$

ERCP indicates endoscopic retrograde cholangiopancreatography, SD standard deviation, IQR interquartile range 
Table 2 Dose area product (DAP), fluoroscopy time (FT) and radiographic images by different variables in 638 ERCP procedures

\begin{tabular}{|c|c|c|c|c|c|c|}
\hline & \multicolumn{2}{|c|}{$\operatorname{DAP}\left(G y \cdot \mathrm{cm}^{2}\right)$} & \multicolumn{2}{|c|}{ FT (min) } & \multicolumn{2}{|c|}{ Radiographic images } \\
\hline & mean $\pm \mathrm{SD}$ & median [IQR] & mean \pm SD & median [IQR] & mean $\pm \mathrm{SD}$ & median (range) \\
\hline Overall $(n=638)$ & $2.33 \pm 1.79$ & $1.83[1.20-2.90]$ & $1.84 \pm 1.56$ & $1.37[0.90-2.30]$ & $3.02 \pm 1.83$ & $3.0(0-11)$ \\
\hline \multicolumn{7}{|l|}{ Gender } \\
\hline Female $(n=330)$ & $2.11 \pm 1.65$ & $1.68[1.12-2.60]$ & $1.87 \pm 1.50$ & $1.39[1.08-2.32]$ & $2.82 \pm 1.84$ & $2.0(0-11)$ \\
\hline Male $(n=308)$ & $2.55 \pm 1.92$ & $2.14[1.24-3.16]$ & $1.81 \pm 1.62$ & $1.32[0.53-2.31]$ & $3.23 \pm 1.80$ & $3.0(0-9)$ \\
\hline \multicolumn{7}{|l|}{ Age (years) } \\
\hline$<35(n=40)$ & $1.77 \pm 1.18$ & $1.51[0.85-2.54]$ & $1.46 \pm 1.06$ & $1.17[0.52-2.20]$ & $2.80 \pm 1.80$ & $2.0(1-8)$ \\
\hline $36-65(n=223)$ & $2.62 \pm 2.20$ & $1.97[1.25-3.27]$ & $1.98 \pm 1.75$ & $1.42[1.07-2.38]$ & $3.17 \pm 1.90$ & $3.0(0-11)$ \\
\hline$>66(n=375)$ & $2.21 \pm 1.54$ & $1.78[1.14-2.78]$ & $1.80 \pm 1.48$ & $1.34[0.59-2.28]$ & $2.95 \pm 1.79$ & $3.0(0-11)$ \\
\hline \multicolumn{7}{|l|}{ Indication } \\
\hline Bile duct stones $(n=261)$ & $1.97 \pm 1.40$ & $1.54[1.09-2.41]$ & $1.67 \pm 1.38$ & $1.29[0.59-2.13]$ & $2.21 \pm 1.35$ & $2.0(0-9)$ \\
\hline Malignant strictures $(n=100)$ & $2.24 \pm 1.48$ & $1.82[1.18-3.01]$ & $1.79 \pm 1.55$ & $1.39[0.56-2.35]$ & $3.33 \pm 1.57$ & $3.0(0-8)$ \\
\hline Jaundice $(n=80)$ & $2.71 \pm 2.02$ & $2.22[1.30-3.14]$ & $1.99 \pm 1.57$ & $1.54[1.06-2.44]$ & $3.34 \pm 1.95$ & $3.0(1-11)$ \\
\hline Cholangitis $(n=61)$ & $2.60 \pm 2.21$ & $2.12[1.36-2.87]$ & $1.80 \pm 1.25$ & $1.43[1.07-2.27]$ & $3.30 \pm 1.68$ & $3.0(1-8)$ \\
\hline Chronic pancreatitis $(n=28)$ & $2.61 \pm 2.37$ & $2.00[1.28-3.37]$ & $2.19 \pm 1.74$ & $1.94[0.67-3.21]$ & $3.46 \pm 2.19$ & $3.0(0-11)$ \\
\hline Suspicion of bile duct injury $(n=22)$ & $3.90 \pm 2.65$ & $3.61[1.98-5.23]$ & $2.25 \pm 1.87$ & $1.77[1.34-2.37]$ & $4.68 \pm 1.56$ & $5.0(2-8)$ \\
\hline Pseudocyst $(n=8)$ & $2.45 \pm 1.85$ & $1.75[1.06-3.77]$ & $2.26 \pm 1.53$ & $2.21[0.68-3.95]$ & $3.88 \pm 2.23$ & $3.5(2-9)$ \\
\hline Stent exchange or removal $(n=36)$ & $2.19 \pm 1.65$ & $1.38[0.82-3.38]$ & $2.15 \pm 2.25$ & $1.31[0.49-3.39]$ & $3.44 \pm 2.05$ & $3.0(0-8)$ \\
\hline
\end{tabular}


Other $(n=42)$

Type of ERCP

Primary ERCP $(n=463)$

Repeat ERCP $(n=175)$

Primary endoscopist

$$
\begin{aligned}
& 1(n=168) \\
& 2(n=59) \\
& 3(n=229) \\
& 4(n=132) \\
& 5(n=50)
\end{aligned}
$$

Post-ERCP diagnosis

Normal anatomy $(n=65)$

Bile duct stricture $(n=174)$

Bile duct stones $(n=208)$

Cholangitis $(n=48)$

Chronic pancreatitis $(n=26)$

Pseudocyst $(n=6)$

Bile duct dilatation $(n=20)$

Bile duct injury $(n=22)$

Stent problems $(n=16)$

Pancreatic duct leakage $(n=12)$
$2.68 \pm 2.09$

$2.22[1.30-3.49]$

$2.01 \pm 1.97$

$1.19[0.56-3.27]$

$3.83 \pm 2.48$

$3.5(1-11)$

$$
2.21 \pm 1.67
$$

1.80 [1.14-2.70]

$1.74 \pm 1.47$

1.33 [0.58-2.19]

$2.93 \pm 1.81 \quad 2.0(0-11)$

$2.63 \pm 2.06$

2.12 [1.19-3.53]

$2.09 \pm 1.75 \quad 1.45[1.07-2.55]$

$3.25 \pm 1.86 \quad 3.0(0-11)$

$2.42 \pm 2.09 \quad 1.69[1.09-3.24]$

$2.11 \pm 1.87 \quad 1.39[1.01-3.06]$

$3.17 \pm 2.10 \quad 3.0(0-11)$

$1.88 \pm 1.19 \quad 1.67$ [0.92-2.39]

$0.92 \pm 0.91 \quad 0.52$ [0.37-1.29]

$2.41 \pm 1.81$

2.04 [1.30-2.98]

$1.81 \pm 1.40$

1.45 [1.07-2.29]

$1.79 \pm 1.58$

1.31 [1.07-2.16]

$2.25 \pm 1.27$

$2.17[1.40-3.16]$

$2.39 \pm 1.31 \quad 2.24[1.45-3.05]$

$1.63 \pm 1.06 \quad 1.34[0.83-2.12]$

$1.18 \pm 0.87$

$2.37 \pm 1.71$

1.86 [1.23-2.80]

$1.89 \pm 1.59$

1.15 [0.48-1.43]

1.43 [1.01-2.43]

$1.82 \pm 1.43 \quad 1.34$ [1.07-2.18]

$1.82 \pm 1.25 \quad 1.43[1.09-2.44]$

$2.48 \pm 2.27 \quad 1.97$ [0.95-3.47]

$1.46 \pm 1.50 \quad 0.82$ [0.43-2.59]

$1.61 \pm 1.52 \quad 1.09$ [0.47-2.93]

$2.34 \pm 1.84 \quad 1.77$ [1.36-2.69]

$1.95 \pm 1.82$

1.11 [0.43-4.05]

$3.20 \pm 1.95$

$3.23[1.70-4.22]$
$3.27 \pm 1.78 \quad 3.0(1-11)$

$3.14 \pm 1.76 \quad 3.0(0-9)$

$2.63 \pm 1.57 \quad 2.0(0-9)$

$2.64 \pm 1.74 \quad 2.0(0-8)$

$\begin{array}{ll}2.49 \pm 1.64 & 2.0(1-7) \\ 3.64 \pm 1.83 & 3.0(0-11) \\ 2.22 \pm 1.35 & 2.0(0-9) \\ 3.19 \pm 1.62 & 3.0(1-8) \\ 3.23 \pm 1.77 & 3.0(0-7) \\ 3.33 \pm 1.03 & 4.0(2-4) \\ 3.60 \pm 2.14 & 3.0(1-9) \\ 4.77 \pm 1.45 & 5.0(2-8) \\ 2.69 \pm 1.82 & 2.0(0-7) \\ 4.25 \pm 2.77 & 4.0(1-11)\end{array}$


Other $(n=41)$

Complexity level of ERCP

$$
\begin{aligned}
& 1(n=125) \\
& 2(n=381) \\
& 3(n=132)
\end{aligned}
$$

Cannulation difficulty of ERCP

$$
1(n=216)
$$

$2(n=181)$

$3(n=140)$
$2.66 \pm 2.20$

$2.15[1.08-3.49]$

$1.88 \pm 1.92$

$1.14[0.51-2.35]$

$3.39 \pm 2.32$

$3.0(0-9)$

$\begin{array}{llllll}2.22 \pm 1.76 & 1.73[0.98-2.78] & 1.77 \pm 1.71 & 1.31[0.50-2.34] & 3.46 \pm 1.90 & 3.0(0-9) \\ 2.18 \pm 1.76 & 1.74[1.11-2.68] & 1.65 \pm 1.40 & 1.27[0.58-2.17] & 2.91 \pm 1.80 & 2.0(0-11) \\ 2.84 \pm 1.85 & 2.32[1.40-3.67] & 2.45 \pm 1.71 & 2.02[1.27-3.37] & 2.89 \pm 1.80 & 2.0(0-11)\end{array}$

$2.18 \pm 1.71 \quad 1.67[1.08-2.79]$

$1.61 \pm 1.47 \quad 1.25[0.52-2.15]$

$2.89 \pm 1.80 \quad 2.0(0-11)$

$2.20 \pm 1.82 \quad 1.74$ [1.13-2.65]

$1.63 \pm 1.40 \quad 1.25[0.54-2.12]$

$2.98 \pm 1.66 \quad 3.0(0-8)$

$2.61 \pm 1.63 \bigcirc 2.24[1.49-3.23]$

$3.08 \pm 1.80 \quad 3.0(0-9)$

$E R C P$ indicates endoscopic retrograde cholangiopancreatography, $S D$ standard deviation, $I Q R$ interquartile range 
Table 3 The distribution of ERCP procedural complexity by endoscopist

\begin{tabular}{ccrrrrrr}
\hline & & \multicolumn{5}{c}{ Complexity level of ERCP } \\
\cline { 3 - 8 } Endoscopist & Total & \multicolumn{2}{c}{ Grade 1 } & \multicolumn{2}{c}{ Grade 2 } & Grade 3 \\
\hline 1 & 168 & 34 & $(20.2 \%)$ & 90 & $(53.6 \%)$ & 44 & $(26.2 \%)$ \\
2 & 59 & 9 & $(15.3 \%)$ & 39 & $(66.1 \%)$ & 11 & $(18.6 \%)$ \\
3 & 229 & 52 & $(22.7 \%)$ & 139 & $(60.7 \%)$ & 38 & $(16.6 \%)$ \\
4 & 132 & 18 & $(13.6 \%)$ & 76 & $(57.6 \%)$ & 38 & $(28.8 \%)$ \\
5 & 50 & 12 & $(24.0 \%)$ & 37 & $(74.0 \%)$ & 1 & $(2.0 \%)$ \\
Total & 638 & 125 & $(19.6 \%)$ & 381 & $(59.7 \%)$ & 132 & $(20.7 \%)$ \\
\hline
\end{tabular}

$E R C P$ indicates endoscopic retrograde cholangiopancreatography 
Table 4 Univariate and multivariate analysis of factors influencing on dose area product (DAP) in 638 ERCP procedures

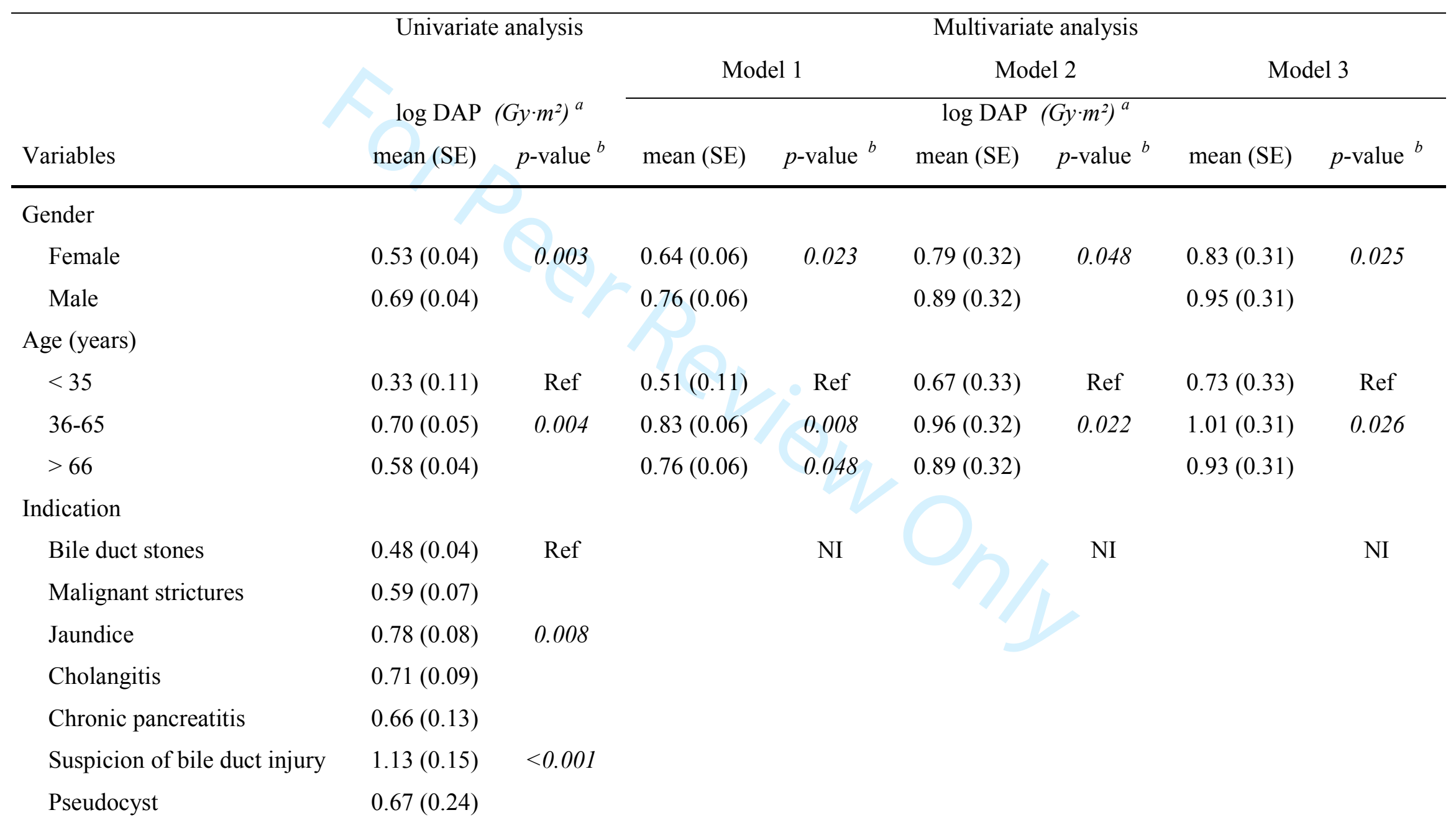


Stent exchange or removal $\quad 0.49(0.11)$

Other

Type of ERCP

Primary ERCP

Repeat ERCP

Primary endoscopist

1

2

3

4

5

Radiographer

1

2

3

4

5

6

7

8

9
$0.72(0.11)$

$0.58(0.03)$

NS

NI

NI

NI

$0.69(0.06)$

$\begin{array}{ll}0.58(0.05) & \text { NS } \\ 0.46(0.09) & \text { Ref } \\ 0.67(0.05) & \\ 0.56(0.06) & \\ 0.71(0.10) & \end{array}$

NI

NI

NI

$\begin{array}{lccccccc}0.20(0.07) & \text { Ref } & 0.26(0.08) & \text { Ref } & 0.41(0.32) & \text { Ref } & 0.47(0.32) & \text { Ref } \\ 0.73(0.06) & <0.001 & 0.86(0.08) & <0.001 & 1.01(0.32) & <0.001 & 1.06(0.31) & <0.001 \\ 0.60(0.18) & & 0.75(0.21) & & 0.86(0.38) & & 0.91(0.38) & \\ 0.69(0.08) & <0.001 & 0.74(0.10) & <0.001 & 0.89(0.33) & <0.001 & 0.93(0.32) & <0.001 \\ 0.71(0.08) & <0.001 & 0.79(0.08) & <0.001 & 0.92(0.32) & <0.001 & 0.97(0.31) & <0.001 \\ 1.26(0.10) & <0.001 & 1.30(0.10) & <0.001 & 1.46(0.33) & <0.001 & 1.52(0.32) & <0.001 \\ 0.21(0.13) & & 0.33(0.12) & & 0.48(0.34) & & 0.51(0.34) & \\ 0.44(0.06) & & 0.47(0.08) & & 0.60(0.32) & & 0.64(0.31) & \\ 0.79(0.14) & <0.001 & 0.82(0.13) & <0.001 & 0.94(0.34) & <0.001 & 1.00(0.33) & <0.001\end{array}$


10

Complexity level of ERCP

1
2
3

Cannulation difficulty of ERCP

1

2

3

Post-ERCP diagnosis

Normal anatomy

Bile duct stricture

Bile duct stones

Cholangitis

Chronic pancreatitis

Pseudocyst

Bile duct dilatation

Bile duct injury

Stent problems

Pancreatic duct leakage

Other

\begin{abstract}
$0.68(0.07)$
\end{abstract}
$<0.001$

$0.71(0.90)$

$<0.001$

$0.85(0.33)$

$<0.001$

$0.90(0.32)$

$<0.001$

$0.52(0.06)$

$<0.001 \quad 0.57(0.08)$

$<0.001$

$0.78(0.35)$

$<0.001$

$0.74(0.32)$

0.014

$0.83(0.34)$

$0.55(0.04)$

$<0.001$

$0.60(0.06)$

Ref

$1.00(0.30)$

Ref

$0.79(0.32)$

0.018

$0.86(0.06)$

$0.54(0.05)$

0.002

$0.57(0.06)<0.001$

$0.70(0.32)$

$<0.001$

$0.76(0.31)$

$0.79(0.32)$

$<0.001$

$0.84(0.31)$

$0.56(0.05)$

0.006

$.65(0.07)$

$1.03(0.32)$

Ref

$1.08(0.32)$

Ref

Ref

$0.88(0.07)$

Ref

$\begin{array}{lcllll}0.29(0.08) & \text { Ref } & 0.36(0.09) & \text { Ref } & 0.61(0.34) & \text { Ref } \\ 0.66(0.05) & <0.001 & 0.72(0.07) & <0.001 & 0.78(0.33) & \\ 0.54(0.05) & & 0.53(0.06) & & 0.77(0.33) & \\ 0.72(0.10) & 0.01 & 0.76(0.09) & 0.01 & 0.88(0.33) & \\ 0.64(0.13) & & 0.60(0.12) & & 0.76(0.32) & \\ 0.51(0.28) & & 0.70(0.26) & & 0.78(0.43) & \\ 0.57(0.15) & & 0.54(0.15) & & 0.80(0.37) & \\ 1.20(0.15) & <0.001 & 1.24(0.13) & <0.001 & 1.32(0.35) & <0.001 \\ 0.52(0.17) & & 0.64(0.18) & & 0.70(0.37) & \\ 1.22(0.20) & <0.001 & 0.89(0.20) & & 0.96(0.36) & \\ 0.65(0.11) & & 0.72(0.10) & 0.03 & 0.90(0.33) & \end{array}$


Types of interventions

Sphincterotomy

NI

NI

$0.79(0.32)$
$0.86(0.34)$

$0.84(0.32)$

Biliary stone extraction

$0.88(0.33)$

$0.91(0.33)$

Bile duct dilatation

Biliary stent placement

Biliary stent removal

$0.95(0.34)$

$0.95(0.33)$

$0.79(0.33)$

0.027

$1.03(0.33)$

0.004

Pancreatic sphincterotomy

$0.88(0.34)$

$0.85(0.32)$

$0.79(0.48)$

$0.91(0.33)$

Pancreatic stone extraction

$0.79(0.38)$

$0.86(0.48)$

Pancreatic duct dilatation

Pancreatic stent placement

$0.96(0.36)$

$0.84(0.36)$

Pancreatic stent removal

$0.89(0.39)$

$1.06(0.35)$

Brushing

$0.88(0.34)$

$0.95(0.37)$

$0.96(0.33)$

$E R C P$ indicates endoscopic retrograde cholangiopancreatography, ${ }^{a}$ distribution of DAP is presented on a logarithmic scale, ${ }^{b}$ Bonferroni adjusted p-values, $S E$ standard error, Ref reference category, NS not significant, $N I$ not included

Types of interventions performed during ERCP were included directly in multivariate analysis 
Table 5 Univariate and multivariate analysis of factors influencing on fluoroscopy time (FT) in 638 ERCP procedures

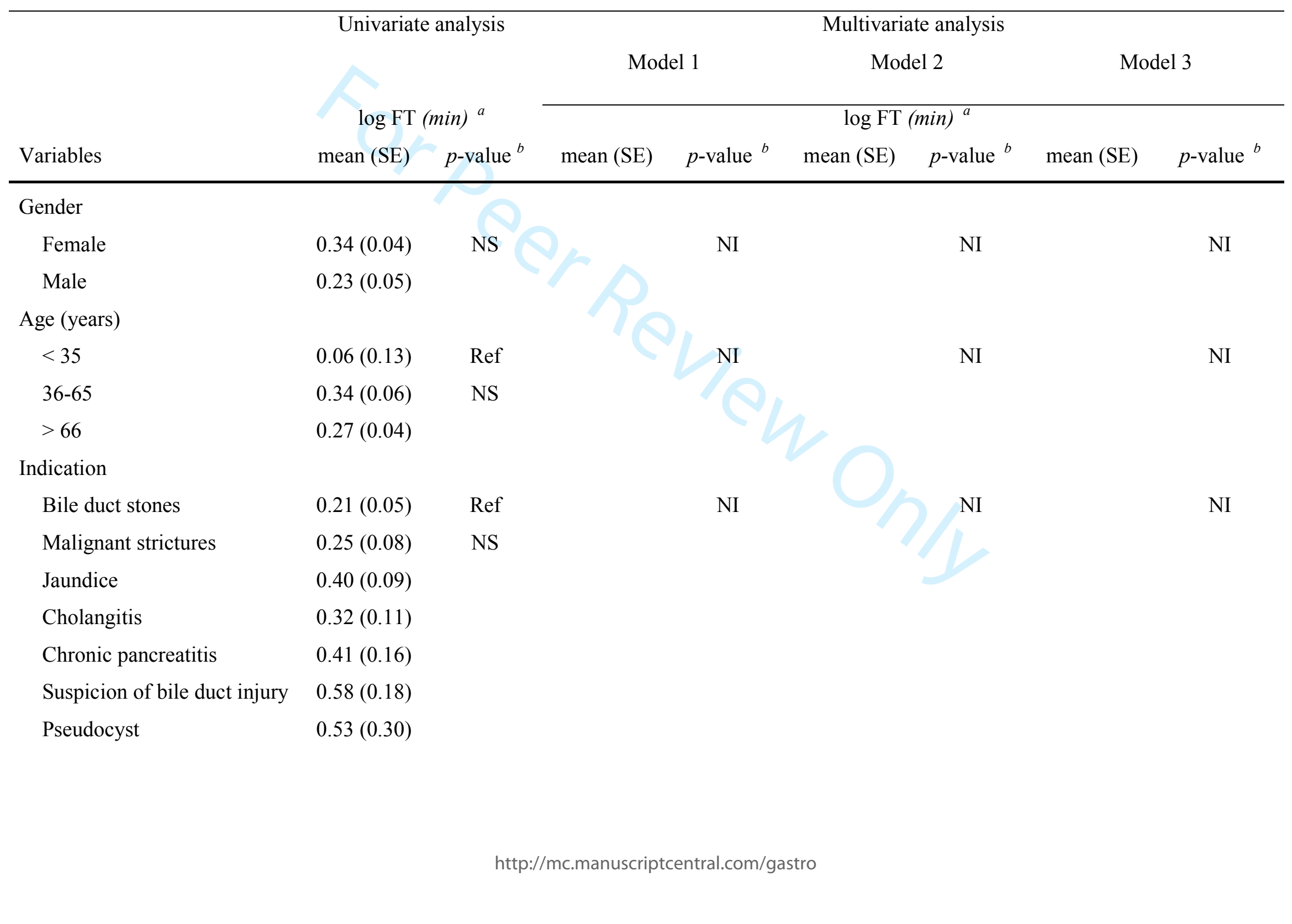




$\begin{array}{ll}\text { Stent exchange or removal } & 0.23(0.14) \\ \text { Other } & 0.29(0.13)\end{array}$

\section{Type of ERCP}

Primary ERCP

$0.25(0.04)$

NS

NI

NI

NI

Primary endoscopist

$0.39(0.07)$

1
2
3
4
5

Radiographer

1

2

3

$\begin{array}{lr}0.38(0.06) & <0.00 \\ -0.42(0.11) & \text { Ref } \\ 0.32(0.05) & <0.00 \\ 0.28(0.07) & <0.00 \\ 0.63(0.11) & <0.00 \\ & \\ 0.14(0.09) & \text { Ref } \\ 0.30(0.08) & \text { NS } \\ 0.34(0.23) & \\ 0.35(0.11) & \\ 0.35(0.10) & \\ 0.53(0.13) & \\ 0.28(0.17) & \\ 0.14(0.08) & \\ 0.49(0.18) & \\ 0.30(0.09) & \end{array}$


Complexity level of ERCP

\begin{tabular}{|c|c|c|c|c|c|c|c|c|}
\hline 1 & $0.13(0.07)$ & $<0.001$ & $0.19(0.09)$ & $<0.001$ & $0.86(0.44)$ & & $1.15(0.43)$ & \\
\hline 2 & $0.21(0.04)$ & $<0.001$ & $0.28(0.07)$ & $<0.001$ & $0.92(0.41)$ & 0.024 & $1.20(0.39)$ & 0.026 \\
\hline 3 & $0.65(0.07)$ & Ref & $0.71(0.09)$ & Ref & $1.23(0.39)$ & Ref & $1.51(0.37)$ & Ref \\
\hline \multicolumn{9}{|l|}{ Cannulation difficulty of ERCP } \\
\hline 1 & $0.13(0.06)$ & $<0.001$ & $0.20(0.07)$ & $<0.001$ & $0.79(0.41)$ & $<0.001$ & $1.08(0.39)$ & $<0.001$ \\
\hline 2 & $0.18(0.06)$ & $<0.001$ & $0.29(0.07)$ & $<0.001$ & $0.92(0.41)$ & $<0.001$ & $1.20(0.39)$ & $<0.001$ \\
\hline 3 & $0.61(0.07)$ & Ref & $0.69(0.08)$ & Ref & $1.31(0.41)$ & Ref & $1.58(0.39)$ & Ref \\
\hline \multicolumn{9}{|l|}{ Post-ERCP diagnosis } \\
\hline Normal anatomy & $-0.12(0.10)$ & Ref & $0.05(0.11)$ & Ref & $0.71(0.43)$ & Ref & & NI \\
\hline Bile duct stricture & $0.32(0.06)$ & $<0.001$ & $0.41(0.07)$ & 0.03 & $0.95(0.42)$ & & & \\
\hline Bile duct stones & $0.32(0.06)$ & $<0.001$ & $0.28(0.07)$ & & $0.87(0.42)$ & & & \\
\hline Cholangitis & $0.33(0.12)$ & & $0.51(0.12)$ & 0.04 & $0.90(0.42)$ & & & \\
\hline Chronic pancreatitis & $0.48(0.16)$ & 0.02 & $0.49(0.15)$ & & $1.19(0.41)$ & & & \\
\hline Pseudocyst & $-0.02(0.34)$ & & $0.13(0.33)$ & & $0.86(0.54)$ & & & \\
\hline Bile duct dilatation & $0.08(0.19)$ & & $0.08(0.19)$ & & $0.77(0.46)$ & & & \\
\hline Bile duct injury & $0.66(0.18)$ & $<0.001$ & $0.78(0.17)$ & $<0.001$ & $1.23(0.44)$ & & & \\
\hline Stent problems & $0.13(0.21)$ & & $0.43(0.23)$ & & $0.90(0.47)$ & & & \\
\hline Pancreatic duct leakage & $0.93(0.24)$ & $<0.001$ & $0.90(0.25)$ & 0.02 & $1.76(0.46)$ & 0.03 & & \\
\hline Other & $0.21(0.13)$ & & $0.26(0.13)$ & & $0.89(0.42)$ & & & \\
\hline \multicolumn{9}{|l|}{ Types of interventions } \\
\hline Sphincterotomy & & NI & & NI & $1.01(0.41)$ & & $1.28(0.40)$ & \\
\hline
\end{tabular}




\begin{tabular}{|c|c|c|c|c|}
\hline Biliary stone extraction & $1.08(0.43)$ & & $1.33(0.41)$ & \\
\hline Bile duct dilatation & $1.13(0.42)$ & 0.037 & $1.43(0.41)$ & 0.014 \\
\hline Biliary stent placement & $1.13(0.43)$ & & $1.44(0.41)$ & 0.008 \\
\hline Biliary stent removal & $1.08(0.42)$ & & $1.36(0.40)$ & \\
\hline Pancreatic sphincterotomy & $1.11(0.43)$ & & $1.39(0.41)$ & \\
\hline Pancreatic stone extraction & $1.12(0.61)$ & & $1.33(0.60)$ & \\
\hline Pancreatic duct dilatation & $0.94(0.48)$ & & $1.40(0.45)$ & \\
\hline Pancreatic stent placement & $1.01(0.45)$ & & $1.40(0.43)$ & \\
\hline Pancreatic stent removal & $1.07(0.49)$ & & $1.54(0.46)$ & \\
\hline Brushing & $1.29(0.44)$ & 0.002 & $1.56(0.41)$ & 0.001 \\
\hline
\end{tabular}

$E R C P$ indicates endoscopic retrograde cholangiopancreatography, ${ }^{a}$ distribution of FT is presented on a logarithmic scale, ${ }^{b}$ Bonferroni adjusted p-values, $S E$ standard error, Ref reference category, $N S$ not significant, $N I$ not included

Types of interventions performed during ERCP were included directly in multivariate analysis 
Fig. 1 The distribution of dose area product (DAP) by radiographer controlled fluoroscopy system during endoscopic retrograde cholangiopancreatography (ERCP)

\section{$21 \times 16 \mathrm{~mm}(300 \times 300 \mathrm{DPI})$}

